\author{
T.J. Loher \\ C.L. Bassetti \\ K.O. Lövblad \\ F.P. Stepper \\ M. Sturzenegger \\ C. Kiefer \\ K. Nedeltchev \\ M. Arnold \\ L. Remonda \\ G. Schroth
}

\title{
Diffusion-weighted MRI in acute spinal cord ischaemia
}

Received: 5 February 2003

Accepted: 14 April 2003

Published online: 27 June 2003

(C) Springer-Verlag 2003
T.J. Loher · C.L. Bassetti · F.P. Stepper M. Sturzenegger $\cdot$ K. Nedeltchev M. Arnold

Department of Neurology, Inselspital, University of Berne, 3010 Berne, Switzerland

K.O. Lövblad $\cdot$ C. Kiefer

L. Remonda · G. Schroth (ه)

Department of Neuroradiology, Inselspital, University of Berne, 3010 Berne, Switzerland

\begin{abstract}
Acute spinal cord ischaemia is often undetectable with conventional MRI. Diffusion-weighted MRI (DWI) has been difficult to use in the spine because of susceptibility artefacts. We assessed the diagnostic value of echoplanar DWI for early confirmation of spinal cord ischaemia. We performed conventional MRI and DWI in two men and three women, aged 54-75 years with clinically suspected acute spinal cord ischaemia. Imaging was performed 9-46 h after the onset of symptoms, and 2-9 days later to assess the extent of ischaemic signal change. Spatial resolution of DWI within the spine using standard equipment was poor, but in all patients, early DWI revealed areas of high signal indicating decreased diffusion,
\end{abstract}

confirmed by measurement of apparent diffusion coefficients. Follow-up MRI showed high signal on T2-weighted images and contrast enhancement at the expected levels. Neurological deficits corresponded with radiological findings in four patients: various syndromes, including isolated bilateral weakness or sensory change and combined deficits, were found. Echoplanar DWI may be helpful for confirmation of spinal cord ischaemia in the acute stage, but follow-up T2-weighted images have superior spatial resolution and correlation with clinical findings and lesion extent.

Keywords Spinal cord infarcts · Diffusion-weighted magnetic resonance imaging

\section{Introduction}

In the absence of well-established diagnostic methods, radiological confirmation of acute stroke has until recently been difficult. Conventional methods such as CT and T2-weighted MRI frequently cannot provide a definitive diagnosis in the very acute stage. Diffusionweighted MRI (DWI), sensitive to water mobility $[1,2]$, is an established method for investigating acute cerebral ischaemia [3,4]. Since the advent of echoplanar imaging (EPI), DWI can be used in clinical practice, but is difficult to apply to the spine with standard EPI techniques, since it is sensitive to changes in the local magnetic field: bone and tissue interfaces cause susceptibility artefacts. Few studies have dealt with the use of DWI for spinal cord ischaemia [5, 6, 7, 8, 9,10]. We report five consecutive patients with acute spinal cord ischaemia who underwent EPI DWI in the acute stage with follow-up imaging. Our aim was to assess the diagnostic value of DWI in the acute stage and clinical correlations with follow-up T2-weighted imaging.

\footnotetext{
Materials and methods

We studied five consecutive patients, aged 54-75 years, with clinically suspected acute spinal cord ischaemia, using conventional MRI and DWI. We used a commercial 1.5 tesla imager capable of EPI. The first study was performed 9, 38, 10, 46 and $12 \mathrm{~h}$ after the onset of symptoms in patients $1-5$, respectively. Follow-up imaging was performed 2-9 days later using conventional sagittal and axial
} 
a T3

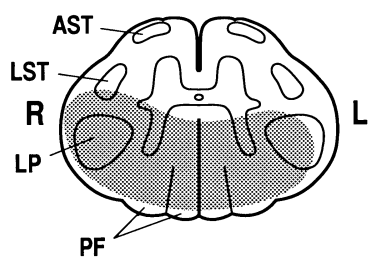

C

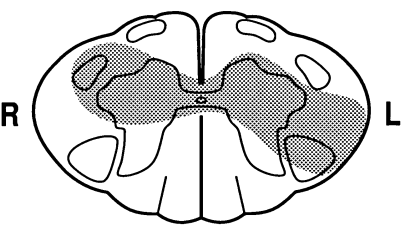

e

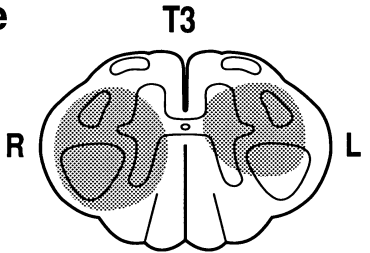

b

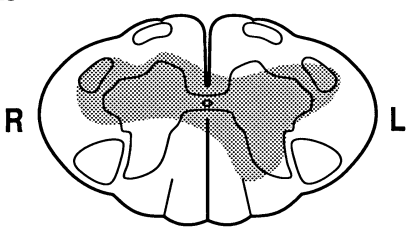

d

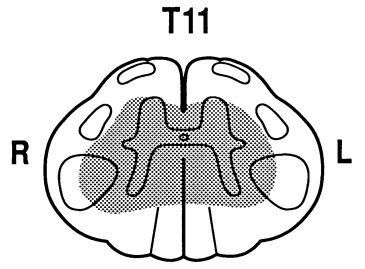

Fig. 1a-e Diagrams of levels with maximum lesion extent as seen on follow-up axial T2-weighted images in each patients. AST anterior spinothalamic tract (light touch); $L P$ lateral pyramidal tract (motor); LST lateral spinothalamic tract (pain and temperature); $P F$ posterior funiculus, including gracile and cuneate fasciculi (posture and vibration sense)

T1- and T2-weighted images with contrast enhancement to assess the extent of ischaemic signal change. We used a spine coil, with a standard head isotropic EPI single-shot spin-echo DWI sequence (TR 5700, TE $139.0 \mathrm{~ms}$, slice thickness $5 \mathrm{~mm}$, one acquisition, field of view $240 \times 240 \mathrm{~mm}, 96 \times 200$ pixels, acquisition time $22 \mathrm{~s}$ ) with $\mathrm{b}$ values of 50,500 and $1000 \mathrm{~s} / \mathrm{mm}^{2}$. We also obtained T2-weighted images in axial (TR 4888 TE $130 \mathrm{~ms}$, slice thickness $4 \mathrm{~mm}$, field

Fig. 2a-c Patient 1. a Axial T2-weighted image $9 \mathrm{~h}$ after onset of symptoms shows slightly high signal posterocentrally in the spinal cord (arrow). b Axial diffusion-weighted image (DWI) at the same time and level, shows high signal in the area corresponding to the spinal cord T12 (arrow). c Axial T2-weighted image $48 \mathrm{~h}$ later more definite high signal at the same site (arrow)
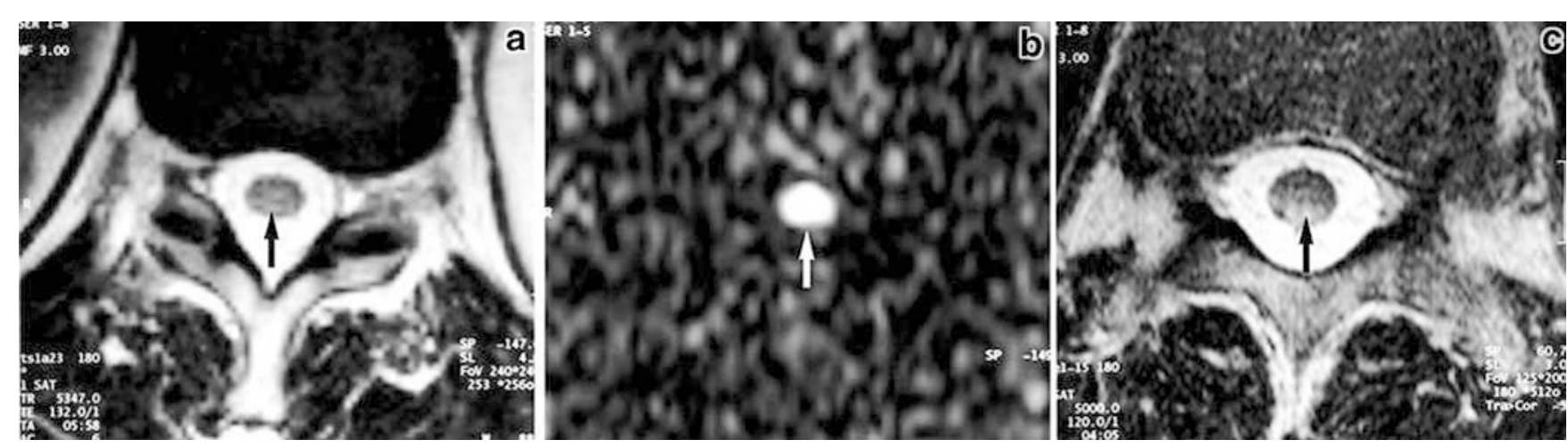

of view $130 \times 260 \mathrm{~mm}, 180 \times 512$ pixels) and sagittal(TR 3500 TE $120 \mathrm{~ms}$, slice thickness $4 \mathrm{~mm}$, field of view $190 \times 380$, $130 \times 512$ pixels) planes. Precise localisation in the horizontal plane was performed by overlaying a grid using the imager console software. Apparent diffusion coefficient (ADC) maps were generated from the DWI on a pixel-by-pixel basis with software supplied by the manufacturer. Regions of interest were defined in areas giving higher signal than unaffected portions of the spinal cord, and ADC measured in them on the console. All patients underwent lumbar puncture to exclude haemorrhagic or inflammatory disorders, and had extensive blood analyses, 12-lead ECG, CT of thorax and abdomen, and transthoracic echocardiography in addition to repeated neurological examination.

\section{Results}

On DWI and T2-weighted images the spinal cord lesion was thoracic in three patients and cervical in two (Fig. 1). In all patients, the early DWI showed high signal in the spinal cord (Figs. 2, 3) corresponding to decreased diffusion as shown by the ADC. Because of the EPI acquisition technique, severe susceptibility artefacts around the spinal cord caused loss of detail of surrounding structures, especially the bones. The initial ADC were: $0.70,0.83,0.87,0.84$ and $0.90 \times 10^{-3} \mathrm{~mm} / \mathrm{s}$ in patients $1-5$, respectively. Three patients had also high signal on $\mathrm{T} 2$-weighted images at 9 (patient 1, Fig. 2a), 38 (patient 2), and $12 \mathrm{~h}$ (patient 5, Fig. 3a) after the onset of symptoms. We saw no abnormality on DWI (Fig. 2b, 3b) or ADC maps (Fig. 3c, d) adjacent to the ischaemic zones, in areas which proved to be unaffected on follow-up imaging. For the latter, we took care to positioned the slice at the same level (Fig. 4). After 2-9 days, T2-weighted images (Fig. 2c) showed high signal in all patients contrast enhancement on T1-weighted images at the relevant sites (Fig. 3d); signal changes were still present on DWI, but less marked.

Detailed clinical information is presented in Table 1. The spinal stroke was preceded by transient ischaemic attacks in three patients, in the form of intermittent attacks of thoracic belt-like pain in patient 1 and intermittent painless leg weakness in patients 3 and 4 . 

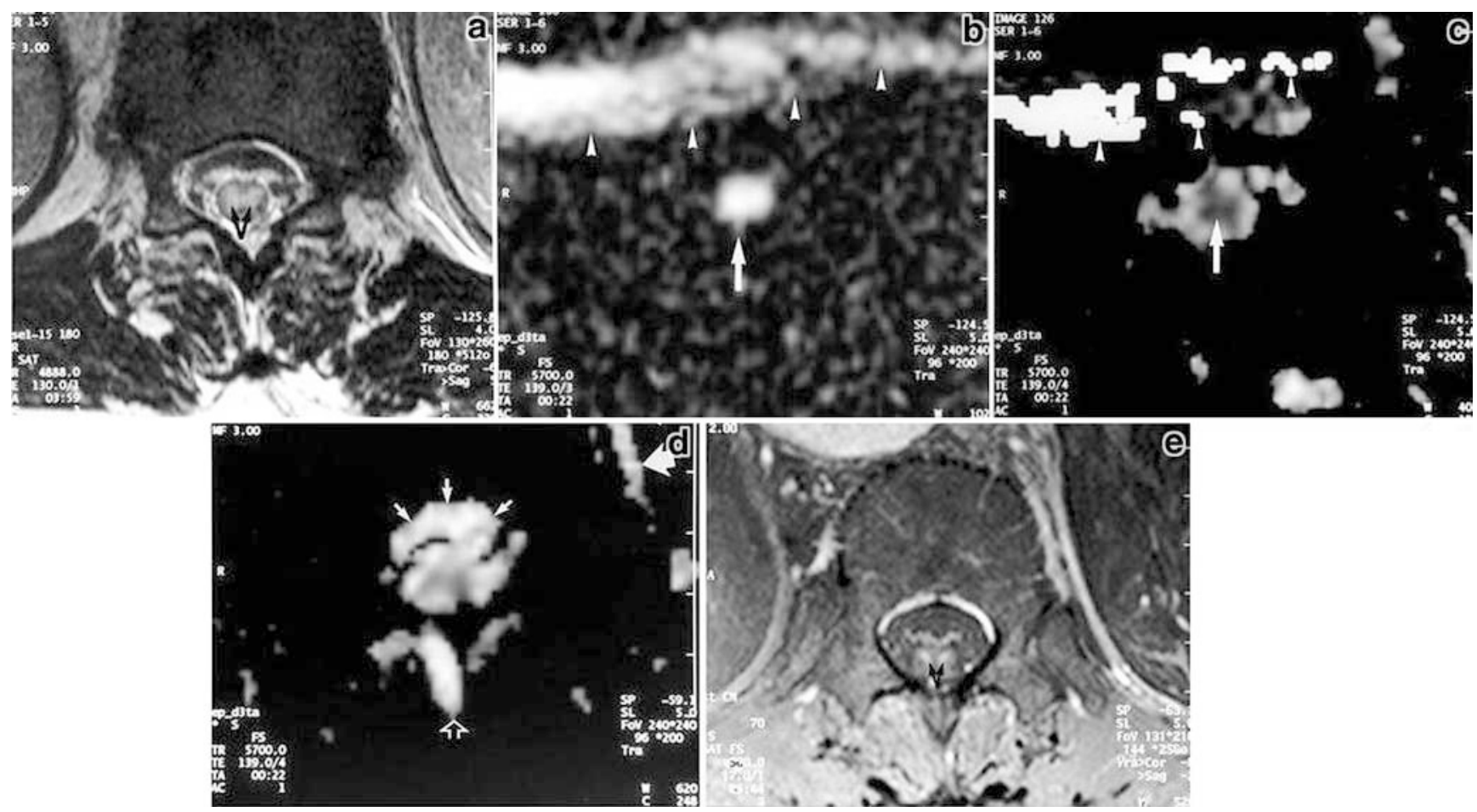

Fig. 3 a-e Patient 5. a Axial T2-weighted image at T11 $12 \mathrm{~h}$ after the onset of symptoms onset shows a large area of high signal centrally in the spinal cord (arrows). b Axial DWI at the same time and level shows high signal (arrow). Note strong chemical-shift artefact above spinal cord (arrowheads). c Axial ADC (apparent diffusion coefficient) map at the same time and level shows a dark area in the spinal cord (arrow). Note susceptibility-related artefactual signal loss (arrowheads). d Axial ADC map 5 days later still shows still low ADC, but less marked. One can also see contour of the left side of the vertebral body (large arrows) and spinous process (open arrow) and the ventral contour of the spinal canal (small arrows). e T1-weighted fat-saturated image after 5 days shows contrast enhancement of the central spinal cord, predominantly in the ventral horns (the "snake bite" pattern) (arrows)

The symptoms of spinal stroke developed within from a few minutes to $12 \mathrm{~h}$. In patients 1,2 and 4 , the initial symptom, before the development of sensory and motor deficits, was transient, lancinating, local or radicular back and/or neck pain. In patient 2, atrial fibrillation was the presumed cause, while in patient 5 , the spinal stroke occurred after grafting of a thoracoabdominal aortic aneurysm. In patients 1,3 and 4 , investigations revealed no specific cause; they all, however, had vascular risk factors: patients 3 and 4 had arterial hypertension, patients 1 and 4 were heavy smokers and patient 3 suffered from hypertriglyceridaemia. Neither cerebrospinal fluid (CSF) and extensive blood tests nor other radiological examinations showed inflammatory, neoplastic or other metabolic disturbances other than the vascular risk factors.

\section{Discussion}

We have demonstrated the use of EPI DWI in acute spinal cord ischaemia. While recent reports have shown that DWI of the spinal cord is feasible and of potential interest, few have addressed its utility in acute spinal cord infarcts. We showed high signal on DWI in all five patients admitted with acute myelopathy. The diagnosis of spinal cord ischaemia could be confirmed on the basis of the history, initial symptoms, CSF analysis and follow-up MRI.

The ADC were reduced in the areas of high signal on DWI. The time course of DWI changes was similar to that reported in the brain [4], and the ADC seem to correlate with those reported in animal experiments [11] or those obtained with interleaved EPI DWI sequences [12]. Murphy et al. [5] found ADC of $1.2 \pm 0.1 \mu \mathrm{m}^{2} / \mathrm{ms}$ in preterm infants, which are higher than those in adults. None of our patients had a vertebral body infarct $[13,14]$. Despite the limited number of patients studied so far, DWI appears to be a sensitive method for early diagnosis of spinal cord ischaemia. However, clinical entities mimicking spinal stroke, such as inflammatory or neoplastic medullary lesions have not, to our knowledge, been fully investigated with DWI. Thus, the specificity of our findings remains to be confirmed. It is probable that, as in the brain, spinal DWI will produce a number of false positives and negatives. In a recent study, Clark et al. [9] found higher diffusion in spinal lesions of multiple sclerosis than in normal volunteers. 
Fig. 4a-d Demonstration of axial slice positioning for two examinations. Left First examination right second. a, b Show precise selection of axial slices c, $\mathbf{d}$ which show the same positioning on scout images and relative to the kidneys and aorta

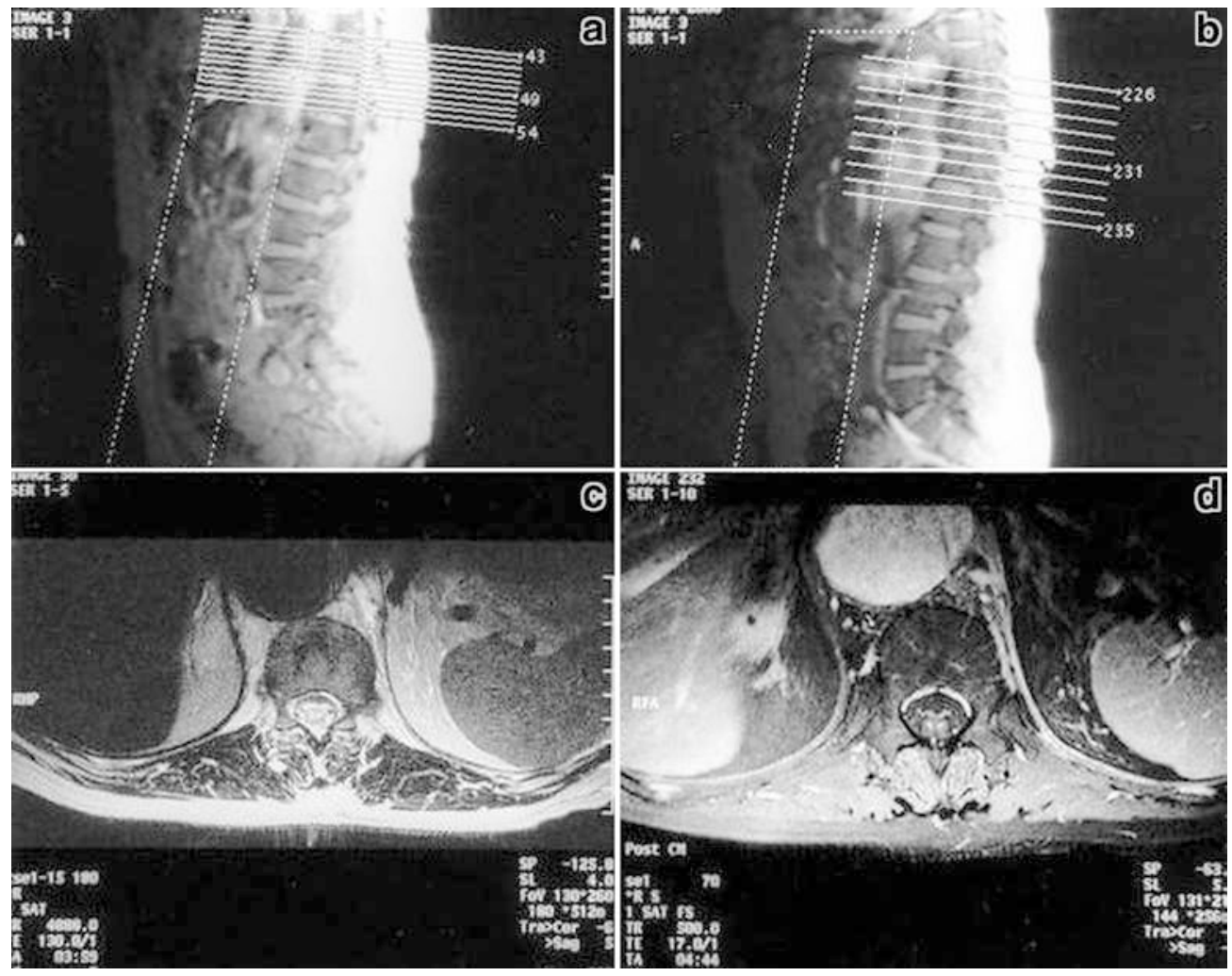

Table 1 Patient characteristics and clinical findings

\begin{tabular}{|c|c|c|c|c|c|c|c|c|}
\hline $\begin{array}{l}\text { Patient, age } \\
\text { (years)/sex }\end{array}$ & $\begin{array}{l}\text { Extent and site } \\
\text { of lesion on } \\
\text { axial T2-weighted } \\
\text { images }\end{array}$ & $\begin{array}{l}\text { Weakness } \\
\text { Site }\end{array}$ & $\begin{array}{l}\text { Grade } \\
\text { (right/left) }\end{array}$ & $\begin{array}{l}\text { Sensory } \\
\text { level }\end{array}$ & Sensory deficits & Hyperreflexia & $\begin{array}{l}\text { Babinski } \\
\text { sign }\end{array}$ & $\begin{array}{l}\text { Bladder } \\
\text { dysfunction }\end{array}$ \\
\hline 1. $60 / \mathrm{M}$ & $\begin{array}{l}\text { T12, bilateral } \\
\text { posterior }\end{array}$ & $\begin{array}{l}\text { Legs } \\
\text { Proximal } \\
\text { Distal }\end{array}$ & $\begin{array}{l}3 / 4 \\
4 / 4\end{array}$ & $\mathrm{~T} 12$ & $\begin{array}{l}\text { Bilateral loss of vibration, } \\
\text { pain and temperature; } \\
\text { loss of touch on the right }\end{array}$ & Right $>$ left & Right & None \\
\hline 2. $75 / \mathrm{F}$ & $\begin{array}{l}\text { C5, left anterior } \\
\text { and right } \\
\text { posterior }\end{array}$ & $\begin{array}{l}\text { Arms } \\
\text { Proximal } \\
\text { Distal } \\
\text { Legs } \\
\text { Proximal } \\
\text { Distal }\end{array}$ & $\begin{array}{l}5 / 3 \\
4 / 1 \\
\\
5 / 4 \\
5 / 4\end{array}$ & $\mathrm{~T} 4$ & $\begin{array}{l}\text { Loss of pain and } \\
\text { temperature on right }\end{array}$ & None & Left & None \\
\hline 3. $74 / F$ & $\begin{array}{l}\mathrm{T} 3 \text {, bilateral } \\
\text { intermediate }\end{array}$ & $\begin{array}{l}\text { Legs } \\
\text { Proximal } \\
\text { Distal }\end{array}$ & $\begin{array}{l}2 / 2 \\
2 / 2\end{array}$ & T6 & $\begin{array}{l}\text { Bilateral loss of pain } \\
\text { and temperature }\end{array}$ & Bilateral & Bilateral & None \\
\hline 4. $58 / \mathrm{F}$ & $\begin{array}{l}\mathrm{C} 3 \text {, bilateral } \\
\text { intermediate }\end{array}$ & None & & $\mathrm{C} 4$ & $\begin{array}{l}\text { Bilateral loss of pain } \\
\text { and temperature; } \\
\text { loss of postural } \\
\text { sensation on left }\end{array}$ & None & None & Yes \\
\hline 5. $54 / \mathrm{M}$ & $\begin{array}{l}\text { T11, bilateral } \\
\text { central }\end{array}$ & $\begin{array}{l}\text { Legs } \\
\text { Proximal } \\
\text { Distal }\end{array}$ & $\begin{array}{l}0 / 0 \\
4 / 4\end{array}$ & None & None & Bilateral & None & None \\
\hline
\end{tabular}

A drawback of the EPI technique is very strong susceptibility artefacts, which destroy most information concerning neighboring structures such as the vertebrae. In order to image stroke, it is necessary to use high values of $b$, to retain sensitivity to ischaemia [15]. This can be done using susceptibility-insensitive methods such as line-scan or HASTE-based DWI [16]. We used a trace image automatically generated by our imager [17]. This has been validated for human cerebral stroke but is more crucial in the spinal cord where tracts are oriented strongly craniocaudally. Even in the brain orientationdependent ADC measurements can induce errors $[18,19]$. 
We confirmed that spinal cord ischaemia can present with a variety of syndromes including isolated bilateral motor or sensory or combined deficits (Table 1). The clinical findings in four patients correlated with maximum axial lesion extent on follow-up T2weighted images (Fig 1). In patient 1, deficits in vibration sense were consistent with a posterior lesion (Fig 1a) including the lateral pyramidal tract and correlated with the motor deficits. In patients 2 and 4 , with atypical presentations, we found a good correlation between clinical and radiological findings (Fig 1b, d). Patient 3, presenting with an anterior spinal artery syndrome showed an anterocentral lesion on axial images (Fig 1c). Patient 5, however, had pure motor deficits whereas MRI showed a central stroke including both dorsal horns (Fig 1e). The lesion on T2weighted images was up to seven vertebrae longer than indicated by the sensory levels, as has been reported previously [20]. The lesions did not all fit with textbook anterior or posterior spinal artery strokes but, given the known extremely variation in individual blood supply to the spinal cord, this is not surprising.
Early DWI may therefore be especially helpful in clinically atypical syndromes.

Despite extensive investigation, we were unable to determine the aetiology of spinal cord ischaemia in three patients. Aetiological studies suggest that most cases of spinal cord ischaemia are secondary to aortic disease (rupture, dissection, aneurysms, malformations), surgery to the aorta, or severe arterial hypotension [21].

DWI may become important for early diagnosis of spinal cord ischaemia. Further studies of larger numbers of patients are needed to determine its sensitivity and DWI should be performed in other causes of myelopathy, such as inflammation, to establish its specificity. Development of sequences less subject to susceptibility effects will increase image quality and thereby spatial resolution. Perfusion imaging of the spine remains to be implemented, but the demand imposed on MRI gradient systems to obtain high-resolution fast multislice perfusion imaging may render it difficult.

Acknowledgments This study was funded in part by a grant from the Swiss National Science Foundation (SNF 3100-66348.01).

\section{References}

1. LeBihan D, Breton E, Lallemand D, Grenier P, Cabanis E, Laval-Jeantet M (1986) MR imaging of intravoxel incoherent motions: application to diffusion and perfusion in neurologic disorders. Radiology 161: 401-407

2. Baird AE, Warach S (1998) Magnetic resonance imaging of acute stroke. $\mathbf{J}$ Cereb Blood Flow Metab 18: 583-609

3. Lövblad KO, Laubach HJ, Baird AE, et al (1998) Clinical experience with diffusion-weighted MR in patients with acute stroke. AJNR 19: 1061-1066

4. Schlaug G, Siewert B, Benfield A, Edelman RR, Warach S (1997) Time course of the apparent diffusion coefficient (ADC) abnormality in human stroke. Neurology 49: 113-119

5. Murphy BP, Zientara GP, Huppi PS, et al (2001) Line scan diffusion tensor MRI of the cervical spinal cord in preterm infants. J Magn Reson Imaging 13: 949-953

6. Holder CA, Muthupillai R, Mukundan S Jr, Eastwood JD, Hudgins PA (2000) Diffusion-weighted MR imaging of the normal human spinal cord in vivo. AJNR 21: 1799-1806

7. Ries M, Jones RA, Dousset V, Moonen CT (2000) Diffusion tensor MRI of the spinal cord. Magn Reson Med 44: 884 892
8. Clark CA, Barker GJ, Tofts PS (1999) Magnetic resonance diffusion imaging of the human cervical spinal cord in vivo. Magn Reson Med 41: 1269-1273

9. Clark CA, Werring DJ, Miller DH (2000) Diffusion imaging of the spinal cord in vivo: estimation of the principal diffusivities and application to multiple sclerosis. Magn Reson Med 43: 133-138

10. Stepper F, Lövblad KO (2001) Anterior spinal artery stroke demonstrated by echo-planar DWI. Eur Radiol 11: 26072610

11. Pattany PM, Puckett WR, Klose KJ, et al (1997) High-resolution diffusionweighted MR of fresh and fixed cat spinal cords: evaluation of diffusion coefficients and anisotropy. AJNR 18: 1049-1056

12. Bammer R, Fazekas F, Augustin M, et al (2000) Diffusion-weighted MR imaging of the spinal cord. AJNR 21: 587-591

13. Faig J, Busse O, Salbeck (1998) Vertebral body infarction as a confirmatory sign of spinal cord ischemic stroke: report of three cases and review of the literature. Stroke 29: 239-243

14. Yuh WT, Marsh EE, Wang AK, et al (1992) MR imaging of spinal cord and vertebral body infarction. AJNR 13: 145-154

15. Maier SE, Gutbjartsson H, Patz S, et al (1998) Line scan diffusion imaging: characterization in healthy subjects and stroke patients. Am J Roentgenol 171: 85-93
16. Lövblad KO, Jakob PM, Chen Q, et al (1998) Turbo spin-echo diffusion-weighted MR of ischemic stroke. AJNR 19: 201-208

17. Weber J, Mattle HP, Heid O, Remonda L, Schroth G (2000) Diffusion-weighted imaging in ischaemic stroke: a follow-up study. Neuroradiology 42: 184-191

18. van Gelderen P, de Vleeschouwer MH, DesPres D, Pekar J, van Zijl PC, Moonen CT (1994) Water diffusion and acute stroke. Magn Reson Med 31: 154 163

19. Ulug AM, Beauchamp N Jr, Bryan RN, van Zijl PC (1997) Absolute quantitation of diffusion constants in human stroke. Stroke 28: 483-490

20. Takahashi S, Yamada T, Ishii K, et al (1992) MRI of anterior spinal artery syndrome of the cervical spinal cord. Neuroradiology 35: 25-29

21. Cheshire WP, Santos CC, Massey EW, Howard JF (1996) Spinal cord infarction: etiology and outcome. Neurology 47: $321-330$ 